\title{
Ymond Trousson, Rousseau par ceux qui l'ont vu, Bruxelles
}

\section{Paola Sosso}

\section{(2) OpenEdition \\ 1 Journals}

\section{Edizione digitale}

URL: http://journals.openedition.org/studifrancesi/34757

DOI: $10.4000 /$ studifrancesi.34757

ISSN: 2421-5856

\section{Editore}

Rosenberg \& Sellier

\section{Edizione cartacea}

Data di pubblicazione: 1 novembre 2005

Paginazione: 423-424

ISSN: 0039-2944

\section{Notizia bibliografica digitale}

Paola Sosso, «Ymond Trousson, Rousseau par ceux qui l'ont vu, Bruxelles», Studi Francesi [Online], 146 (XLIX | II) | 2005, online dal 30 novembre 2015, consultato il 18 avril 2021. URL: http:// journals.openedition.org/studifrancesi/34757; DOI: https://doi.org/10.4000/studifrancesi.34757

Questo documento è stato generato automaticamente il 18 avril 2021.

\section{(c) (i) (9)}

Studi Francesi è distribuita con Licenza Creative Commons Attribuzione - Non commerciale - Non opere derivate 4.0 Internazionale. 


\title{
Ymond Trousson, Rousseau par ceux qui l'ont vu, Bruxelles
}

\author{
Paola Sosso
}

\section{NOTIZIA}

YMOND TROUSSON, Rousseau par ceux qui l'ont vu, Bruxelles, Le Cri édition, 2004, pp. 308.

Ricca miniera di informazioni per lo studioso di Rousseau, appassionante raccolta di testimonianze dirette per il lettore comune, il volume raccoglie una sessantina di testi di visitatori, francesi o stranieri più o meno noti, ammiratori affascinati o ostili memorialisti, che hanno raccontato il loro incontro con uno degli autori che, nel bene e nel male, ha maggiormente attratto l'interesse dell'opinione pubblica. La nascita del «personaggio» Jean-Jacques risale agli anni cinquanta: un fenomeno, un «auteur à paradoxes», un profeta, ma anche un personaggio che ha estrema necessità di farsi notare, così viene descritto Jean-Jacques negli anni che precedono la pubblicazione del secondo discorso. L'antologia di Rayomnd Trousson parte però ancora da più lontano, e precisamente dalla «plume furibonde» del conte di Montaigu, ambasciatore a Venezia, presso il quale fu impiegato come segretario Jean-Jacques nel 1743-1744. Il loro rapporto finì, come è noto, in una terribile lite e nel reciproco disprezzo: non ci si stupisce, quindi, di trovar rappresentato, nella descrizione del conte, «un mauvais valet», insolente e pieno di sé, esplicito nel far mostra della sua presunta superiorità. Non certo positivi i ritratti lasciati da Mme de Graffigny e da Mme d'Epinay redatti negli anni cinquanta; da segnalare il giudizio di Casanova, che, nel 1758, non pare particolarmente colpito dal personaggio, definito poco «aimable» e non particolarmente interessante «ni par sa personne ni par son esprit». La lettura delle varie testimonianze lascia trasparire una serie di clichés (la descrizione della casa, la conversazione, il ritratto del ginevrino, la sua voce, il suo sguardo...), cui non di rado si affiancano alcune considerazioni su un mal celato orgoglio che sfocia sovente, come scrive Joseph Clos nel 1774, in una «manie della célébrité» (p. 227). Molti visitatori, tra cui Mme de Graffigny, Pierre Mouchon, J. H. Meister, Mme de Genlis, sono ammaliati 
dagli occhi, specchio dell'anima: sono "pleins de feu», scrive Bjômstahl, nel 1770, e gli fa eco, tra gli altri, Pierre Picot, che parla, nel 1771, di «extrême vivacité des petits yeux noirs». Molti i riferimenti a Thérèse, vero Cerbero, «mauvaise langue» secondo molti, ma dotata di un gran cuore secondo Donin de Champagneux, che scrive nel 1768, anno del matrimonio della coppia ormai non più giovane. Alcuni trovano Jean-Jacques indulgente e moderato (Meister, Corancez), altri, come François Favre, lo descrivono come più impulsivo e iracondo, soprattutto nei confronti di Voltaire. Numerosi gli esempi della generosità del ginevrino verso i bisognosi, continui i riferimenti alla sua instancabile attività di copista, frequente il disappunto di chi trova inadeguata la situazione dello scrittore al suo genio letterario: «J'avais le cœur navré»; - scrive Goldoni (probabilmente nel 1771), - voir l'homme de lettres faire le copiste; voir sa femme faire la servante» (p. 198). Gli esempi delle testimonianze potrebbero certamente moltiplicarsi, vista la ricchezza del volume, da quelle più note di Hume, Grimm, Boswell, Bovier, Moultou, Girardin, Delyre, a quelle più preziose, perché più difficilmente rintracciabili, dei molti visitatori quasi sconosciuti che lasciarono aneddoti e riflessioni ispirate alla persona di Rousseau. Numerose le descrizioni relative agli ultimi anni e all'incupirsi dell'umore di Rousseau, come quello di Aurore de Saxe, ammaliata lettrice della Nouvelle Héloise, che parla nel 1777 di un Jean-Jacques «sauvage et retiré, atteint de cette misanthropie qui fut trop cruellement raillée par ses amis paresseux ou frivoles» (p. 241). Il fervore della visita a Rousseau continuerà dopo il 1778 e sfiorerà, dopo la sua morte, il feticismo: si svilupperà infatti un vero culto per «les sabots, la tabatière, la canne». Il volume include, come si è detto, solo le testimonianze dirette, e raccoglie nelle ultime pagine il resoconto di chi, come Pierre Prévost, ha seguito Jean-Jacques nella vecchiaia, e ha potuto lasciarci un ultimo quadro delle sue inestinguibili passioni, la botanica, la musica, le passeggiate all'aria aperta. 